\title{
ACOLHIMENTO À PESSOA COM O VÍRUS DA IMUNODEFICIÊNCIA HUMANA: REPRESENTAÇÕES SOCIAIS DE PROFISSIONAIS DE SAÚDE
}

\author{
USER-EMBRACEMENT FOR THE PERSON WITH \\ THE HUMAN IMMUNODEFICIENCY VIRUS: SOCIAL \\ REPRESENTATIONS OF HEALTH PROFESSIONALS
}

\section{ACOGIDA A LA PERSONA CON EL VIRUS DE INMUNODEFICIENCIA HUMANA: REPRESENTACIONES SOCIALES DE LOS PROFESIONALES DE LA SALUD}

\author{
Fabiane da Silva Santos ${ }^{1}$ \\ Cleuma Sueli Santos Suto ${ }^{2}$ \\ Taciane Oliveira Bet Freitas ${ }^{3}$ \\ Silvana Gomes Nunes Piva ${ }^{4}$ \\ Rita de Cassia Dias Nascimento \\ Gizélia dos Santos Souza ${ }^{1}$
}

Como citar este artigo: Santos FS, Suto CSS, Freitas TOB, Piva SGN, Nascimento RCD, Souza GS. Acolhimento à pessoa com o vírus da imunodeficiência humana: representações sociais de profissionais de saúde. Rev baiana enferm. 2019;33:e27769.

Objetivo: desvelar as representações sociais de profissionais de saúde da atenção básica sobre o acolhimento à pessoa com o vírus da imunodeficiência humana. Método: trata-se de um estudo exploratório com abordagem qualitativa, embasado na Teoria das Representações Sociais. Participaram da pesquisa 39 profissionais de saúde da rede de atenção básica, no período de outubro e novembro de 2016, respondendo a um questionário. Os dados foram processados pelos softwares EVOC e IRAMUTEQ. Resultados: o termo mais evocado foi "esclarecimento" e retrata que a prática do aconselhamento requer preparação de maneira adequada e qualificada ou aponta que o profissional é o detentor do saber. Conclusão: as representações sociais de profissionais de saúde da atenção básica revelam-se como normativas e hegemônicas, objetivando-se no esclarecimento e na prevenção. Demarcam, possivelmente no cotidiano das ações de aconselhamento/acolhimento, o lugar que os profissionais de saúde ocupam.

Descritores: Acolhimento. Aconselhamento. Profissional de Saúde. HIV. Atenção Primária à Saúde.

Objective: to reveal the social representations of health care professionals regarding primary bealth care for the person with the human immunodeficiency virus. Method: this is an exploratory study with a qualitative approach, based on the Social Representations Theory. Thirty-nine health professionals from the primary care network participated in the study by responding to a questionnaire, in October and November of 2016. The data were processed by the EVOC and

Estudante de Enfermagem. Universidade do Estado da Bahia, Campus VII. Senhor do Bonfim, Bahia, Brasil.

Enfermeira. Mestre em Enfermagem. Professora da Universidade do Estado da Bahia, Campus VII. Senhor do Bonfim, Bahia, Brasil. cleuma.suto@gmail.com

Enfermeira. Mestre em Enfermagem. Professora Assistente da Universidade Salvador - UNIFACS. Feira de Santana, Bahia, Brasil.

Enfermeira. Mestre em Gestão e Tecnologia aplicada a Educação. Professora Assistente da Universidade do Estado da Bahia, Campus VII. Senhor do Bonfim, Bahia, Brasil.

Enfermeira. Especialista em Obstetrícia. Professora Substituta na Universidade do Estado da Bahia, Campus VII. Senhor do Bonfim, Bahia, Brasil. 
IRAMUTEQ software. Results: the most evoked term was "clarification" and portrays that the practice of counseling requires adequate and qualified preparation or that the professional is the holder of knowledge. Conclusion: the social representations of primary bealth care professionals are seen as normative and hegemonic, aimed at clarification and prevention. They highlight the possible places that health professionals occupy in the quotidian of the counseling/ user-embracement actions.

Descriptors: User Embracement. Counseling. Health Personnel. HIV. Primary Health Care.

Objetivo: desvelar las representaciones sociales de los profesionales de la salud de la atención básica sobre la acogida a la persona con el virus de inmunodeficiencia humana. Método: se trata de un estudio exploratorio con abordaje cualitativo, basado en la Teoría de las Representaciones Sociales. Participaron en la investigación 39 profesionales de la salud de la red de atención básica, en el periodo de octubre y noviembre de 2016, respondiendo a un cuestionario. Los datos se procesaron con el softwares EVOC e IRAMUTEQ. Resultados: el término más mencionado fue "esclarecimiento" y retrata que la práctica del asesoramiento requiere preparación de manera adecuada y calificada o señala que el profesional es el poseedor del saber. Conclusión: las representaciones sociales de los profesionales de la salud de la atención básica se manifiestan como normativas y hegemónicas, objetivándose en el esclarecimiento y en la prevención. Demarcan, posiblemente en el cotidiano de las acciones del asesoramiento/ acogida, el lugar que los profesionales de salud ocupan.

Descriptores: Acogida. Asesoramiento. Profesional de Salud. VHI. Atención Primaria de la salud.

\section{Introdução}

No cenário brasileiro de 2007 até junho de 2017, foram notificados, no Sistema de Informação de Agravos e Notificação (SINAN), 194.217 casos de infecção pelo vírus da imunodeficiência humana $(\mathrm{HIV})^{(1)}$. O estigma de que a doença predomina em homens que fazem sexo com homens (HSH), profissionais do sexo e usuários de drogas injetáveis vem sendo desconstruído frente às atuais mudanças no perfil epidemiológico ${ }^{(2)}$. De modo que se faz necessário enfatizar o acolhimento e o aconselhamento às pessoas que vivem com HIV na atenção básica (AB), considerada porta de entrada para todo e qualquer serviço de saúde no Sistema Único de Saúde (SUS).

Os serviços de saúde devem garantir confidencialidade e acesso humanizado para quem deseja realizar o diagnóstico por meio do teste anti-HIV, como para qualquer outra infecção sexualmente transmissível (IST). Desse modo, toda a equipe multiprofissional precisa estar envolvida, para que o/a usuário/a sinta-se acolhido/a, sem discriminação, independentemente de sua atividade profissional, orientação sexual ou identidade de gênero ${ }^{(3)}$.

Acolher a Pessoa Portadora do Vírus da aids (PVH) implica em sua inclusão nos diversos serviços de saúde. A experiência da equipe da atenção básica, adquirida ao lidar com pessoas que vivem com outras doenças crônicas, proporciona-lhe um saber-fazer aperfeiçoado, visando a integralidade no cuidado, no atendimento às necessidades individuais e coletivas que rodeiam o HIV/aids ${ }^{(4)}$.

Nas unidades de saúde, para que o aconselhamento seja realizado, o diálogo e a escuta qualificada são imprescindíveis. Estes só podem estabelecer-se em um ambiente acolhedor e com espaço físico adequado, de maneira que as questões de foro íntimo e intersubjetivas possam ser discutidas. Nesse sentido, é preciso que sejam garantidas a manutenção do sigilo, a privacidade das informações e uma adequada abordagem acerca das situações que ali serão discutidas ${ }^{(5)}$.

O aconselhamento constitui-se em um diálogo entre profissionais de saúde e usuários, e tem base na relação de confiança, com o objetivo de oportunizar condições para que esses usuários possam avaliar seus próprios riscos, tomar decisões e encontrar formas reais de enfrentar seus problemas, inclusive os relacionados às IST/HIV/aids ${ }^{(3)}$.

As unidades básicas de saúde, na rede de atenção do SUS, oferecem a primeira oportunidade para a realização do diagnóstico de HIV em 
pessoas assintomáticas e naquelas que já apresentam sintomas. O pedido de testagem pode surgir de uma demanda espontânea do usuário ou de protocolos seguidos por profissionais de saúde nas rotinas programáticas da atenção básica $^{(6)}$.

A prática do aconselhamento pode ser entendida como um tipo especial de acolhimento no qual a oferta da testagem pode surgir como necessidade de saúde para o usuário. Nesse sentido, o acolhimento é uma técnica de conversa, um diálogo que pretende identificar a compreensão das necessidades do usuário e sua singularidade, de maneira ampla, em uma rede de conversação ${ }^{(6-7)}$.

Ao associar acolhimento e cuidado empático, os efeitos deletérios do diagnóstico de HIV positivo podem amenizar o sofrimento durante a constância do seu acompanhamento. A postura de cuidar, acolher e compreender no processo saúde-doença enfatiza valores como fé, esperança, confiança, necessidades humanas, ética e $\operatorname{moral}^{(8)}$.

As representações sociais (RS) são importantes componentes para a abordagem profissional do HIV/aids, e tornam possível a apreensão dos processos de construção do significado social do objeto nas relações cotidianas dos sujeitos, de forma individual ou coletiva, o que permite reconstituir o simbolismo que sustenta as práticas de cuidado em saúde ${ }^{(9)}$.

Espera-se que este estudo singularize-se por trazer informações pertinentes sobre as práticas de acolhimento prestado por profissionais de saúde na rede de atenção básica relacionadas à pessoa vivendo com HIV, contribuindo para uma percepção crítica que melhore a assistência e as práticas de acolhimento nos serviços de saúde. Este artigo teve como questão norteadora: Quais são as representações sociais dos profissionais da atenção básica sobre o acolhimento à pessoa vivendo com $\mathrm{HIV} /$ aids?

Nesse contexto, o objetivo foi desvelar as representações sociais de profissionais de saúde da atenção básica sobre o acolhimento à pessoa com o vírus da imunodeficiência humana.

\section{Método}

Trata-se de um estudo exploratório descritivo, com abordagem qualitativa, embasado na Teoria das Representações Sociais (TRS). Esta pode ser entendida como uma forma de conhecimento desenvolvida e compartilhada socialmente, composta de informações, crenças, opiniões e atitudes relacionadas a um dado objeto social, que, por sua vez, colabora para a elaboração de uma realidade comum a um determinado grupo social $^{(10)}$.

A pesquisa aconteceu na cidade de Senhor do Bonfim (BA) e contou com a participação de profissionais de saúde da rede de atenção básica, que atuam na estratégia de saúde da família (ESF), no Núcleo de Saúde da Família (NASF) e em Unidades Básicas de Saúde (UBS) onde os serviços de testagem rápida para HIV/IST/Hepatites estão implantados e com acesso facilitado por serem campos de prática da universidade de origem desta pesquisa. Dentre os 43 profissionais com ensino superior, 39 compuseram a amostra nas categorias: médico (10), enfermeiro (15), odontólogo (4), psicólogo (2), fisioterapeuta (5), assistente social (1), educador físico (1) e nutricionista (1). A coleta de informações para a preparação do banco de dados aconteceu no período de outubro e novembro de 2016.

Os critérios de inclusão para a participação nesta pesquisa foram: possuir formação acadêmica, ter vínculo empregatício com a Secretaria Municipal de Saúde por contrato ou concurso público, trabalhar há, no mínimo, seis meses no município e atuar na assistência às pessoas com HIV. Foram excluídos da pesquisa os profissionais que gozavam de férias ou licença (4) no momento da coleta de dados.

O instrumento de coleta foi composto por um roteiro contendo questões referentes ao perfil socioprofissional dos/as participantes: sexo, idade, tempo de atuação, tipo de vínculo empregatício e sobre o desenvolvimento do seu trabalho; e a Técnica de Associação Livre de Palavras (TALP), por meio do termo indutor "Acolhimento em IST/HIV/aids". Durante a aplicação da técnica, solicitou-se aos participantes a 
pronúncia de cinco palavras ou expressões que lhes viessem à mente, relacionadas ao termo indutor, o que possibilitou evidenciar o universo do objeto em estudo.

A organização dos dados iniciou-se com a tematização das evocações, ocorrendo a substituição de palavras com o mesmo significado pela palavra que foi a mais evocada, buscando-se, assim, uniformidade de sentido lexical ${ }^{(11)}$. Em seguida, os dados foram tratados em três etapas: criação de um banco de dados no programa Microsoft Word, contendo a identificação codificada de cada participante com as evocações em ordem direta; criação de outro banco de dados com as palavras ou expressões evocadas na ordem de importância que foi determinada pelo participante, que compuseram o corpus utilizado pelo software EVOC (Ensemble de Programas permettant I' Analyse de Évocations), versão 2005; e criação de mais um banco, no programa Microsoft Excel, com matriz de evocações, processado pelo IRAMUTEQ (Interface de $R$ pour les Analyses Multidimensionnelles de Textes et de Questionnaires).

O software EVOC é um programa informatizado constituído de subprogramas que permitem a emissão de dados e consequentes análises das palavras ou expressões evocadas. Suas frequências simples, ordens médias e distribuição da evocação geram como produto um quadro de quatro casas, com primeiro quadrante, denominado de núcleo central; dois quadrantes, chamados de sistema periférico próximo; e o último quadrante nomeado de sistema periférico distante $^{(11)}$.

O software EVOC possibilitou a confecção do quadro de quatro casas, que localiza os elementos do núcleo central e os elementos periféricos das representações sociais, divide-se em quatro quadrantes e combina dois aspectos - frequência e ordem em que foram evocadas - relacionados às palavras ou às expressões evocadas, possibilitando a distribuição dos termos produzidos segundo a importância atribuída pelos sujeitos $^{(12)}$.

O software IRAMUTEQ é um programa informático que permite diferentes tipos de análise de dados textuais, compreendendo desde cálculos de frequência de palavras, classificação hierárquica descendente até análises de similitude. O programa organiza e distribui o vocabulário de forma simples e clara, apresentando os resultados por meio gráficos. A análise de similitudes permite verificar a quantidade de laços ou conexões mantidos entre um dado elemento e outros elementos, possibilitando evidenciar a estrutura da representação que se configura em forma de árvore máxima de similitude ${ }^{(13)}$.

A análise baseou-se na teoria do núcleo central, abordagem da Teoria das Representações Sociais, que traz como ideia principal a possibilidade da organização de uma representação social manifestar-se em torno de um ideário imagético central, constituído por um ou mais elementos, que concedem sentido à representação. O núcleo central na TRS é definido pelo tipo e pela natureza do objeto representado, pelas relações que o grupo mantém com esse objeto e pelo sistema de valores e normas sociais que compõem o ambiente e as concepções do grupo $^{(14)}$.

Foram obedecidas as normas e diretrizes para a realização de estudos envolvendo seres humanos, de acordo com padrões éticos. Este estudo, que se constitui em um recorte do projeto intitulado Aconselhamento em IST/HAIV/aids: uma Estratégia de Prevenção em Unidades Básicas de Saúde, foi apreciado e aprovado pelo Comitê de Ética e Pesquisa da Universidade do Estado da Bahia sob parecer de número 1.628.938, de 8 de julho de 2016.

\section{Resultados}

Quanto à caracterização dos 39 colaboradores, verificou-se que 24 possuíam idade maior que 35 anos, 31 autodenominaram-se mulheres, 35 tinham grau de especialista e 2, grau de doutorado. Diante dos dados socioprofissionais, obtidos por meio das respostas dos participantes às questões de múltipla escolha, na qual poderiam considerar mais de uma opção, identificou-se que, dentre as atividades desenvolvidas no serviço e orientadas especificamente 
ao atendimento de pessoa com HIV, as mais frequentes foram atividades educativas $(70,2 \%)$ e consulta/atendimento $(62,1 \%)$, conforme demonstra a Tabela 1.

Tabela 1 - Distribuição das atividades desenvolvidas pelos profissionais de saúde na atenção básica à pessoa com HIV. Senhor do Bonfim, Bahia, Brasil - 2018

\begin{tabular}{l|cc}
\hline Atividade & $\mathbf{n}$ & $\mathbf{\%}$ \\
\hline Atividade educativa & 26 & 70,2 \\
Atendimento e suporte para a companheira/o ou família & 13 & 35,1 \\
Aconselhamento individual/coletivo em pré-teste ou pós-teste & 17 & 45,9 \\
Consulta/atendimento & 23 & 62,1 \\
Distribuição de preservativos & 18 & 48,6 \\
Notificação epidemiológica & 15 & 40,5 \\
Oferta de exame & 20 & 54,0 \\
Recepção e aconselhamento & 17 & 45,9 \\
Realização do teste rápido & 12 & 32,4 \\
\hline
\end{tabular}

Fonte: Elaboração própria.

Observa-se que, como resposta ao termo indutor "Acolhimento em IST/HIV/AIDS", os participantes evocaram 230 termos com Ordem Média de Evocação (OME) de 2,7. No processamento dos dados, foram desprezadas as evocações com frequência menor que 3 e estabeleceu-se a frequência intermediária de evocação (FIE) de 8,0. Obteve-se um aproveitamento de 89,6\% do corpus, o que corresponde à manutenção de 206 evocações na amostra analisada (Quadro 1).

Quadro 1 - Quadro de quatro casas ao termo indutor acolhimento em IST/HIV/AIDS. Senhor do Bonfim, Bahia, Brasil - 2018

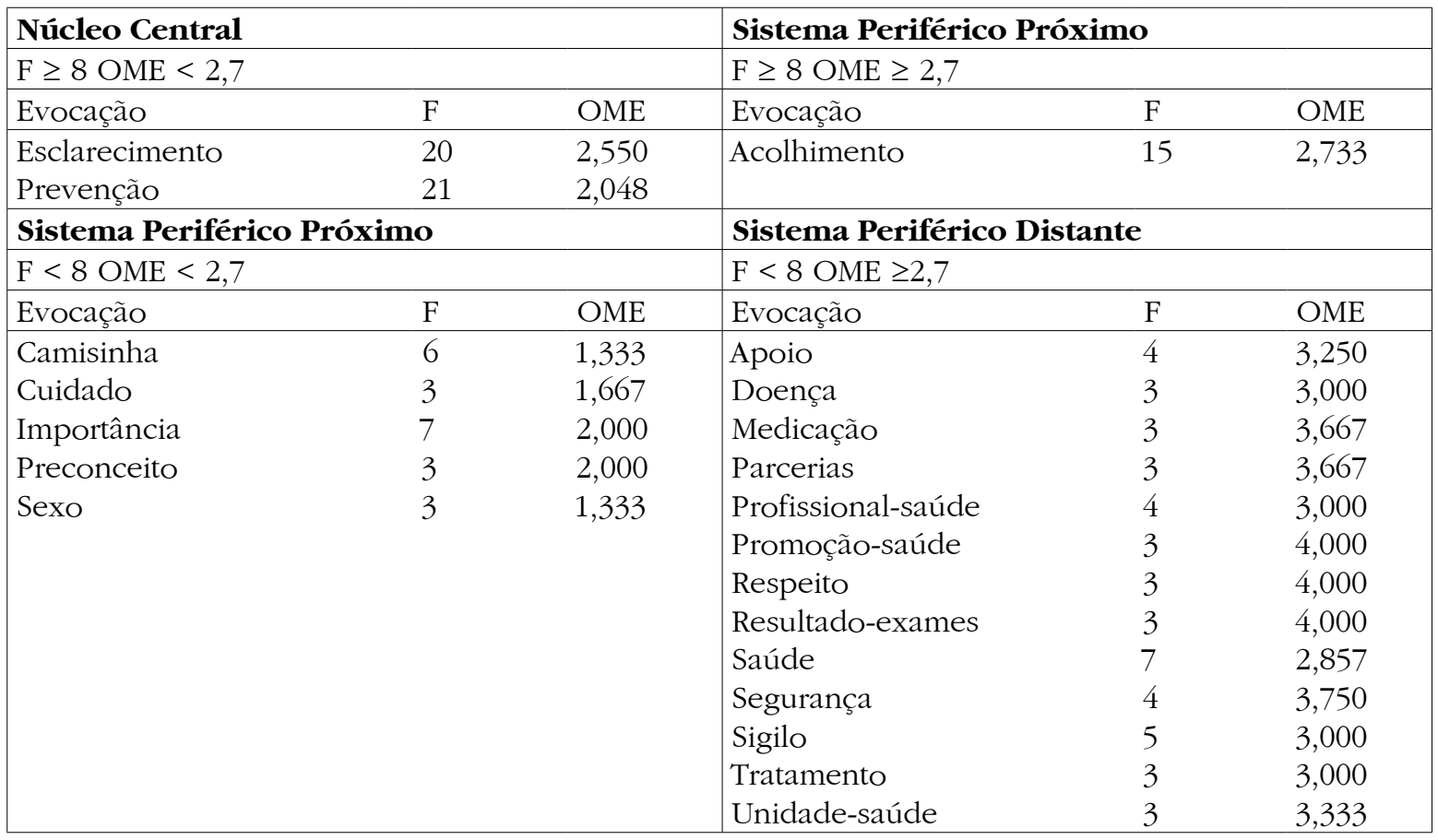

Fonte: Elaboração própria.

Para a elaboração da árvore de similitudes, as evocações que compuseram o terceiro corpus foram processadas pelo software IRAMUTEQ e resultaram na Figura 1. 
Figura 1 - Árvore de Similitudes ao termo indutor "Acolhimento em IST/HIV/AIDS". Senhor do Bonfim, Bahia, Brasil - 2018

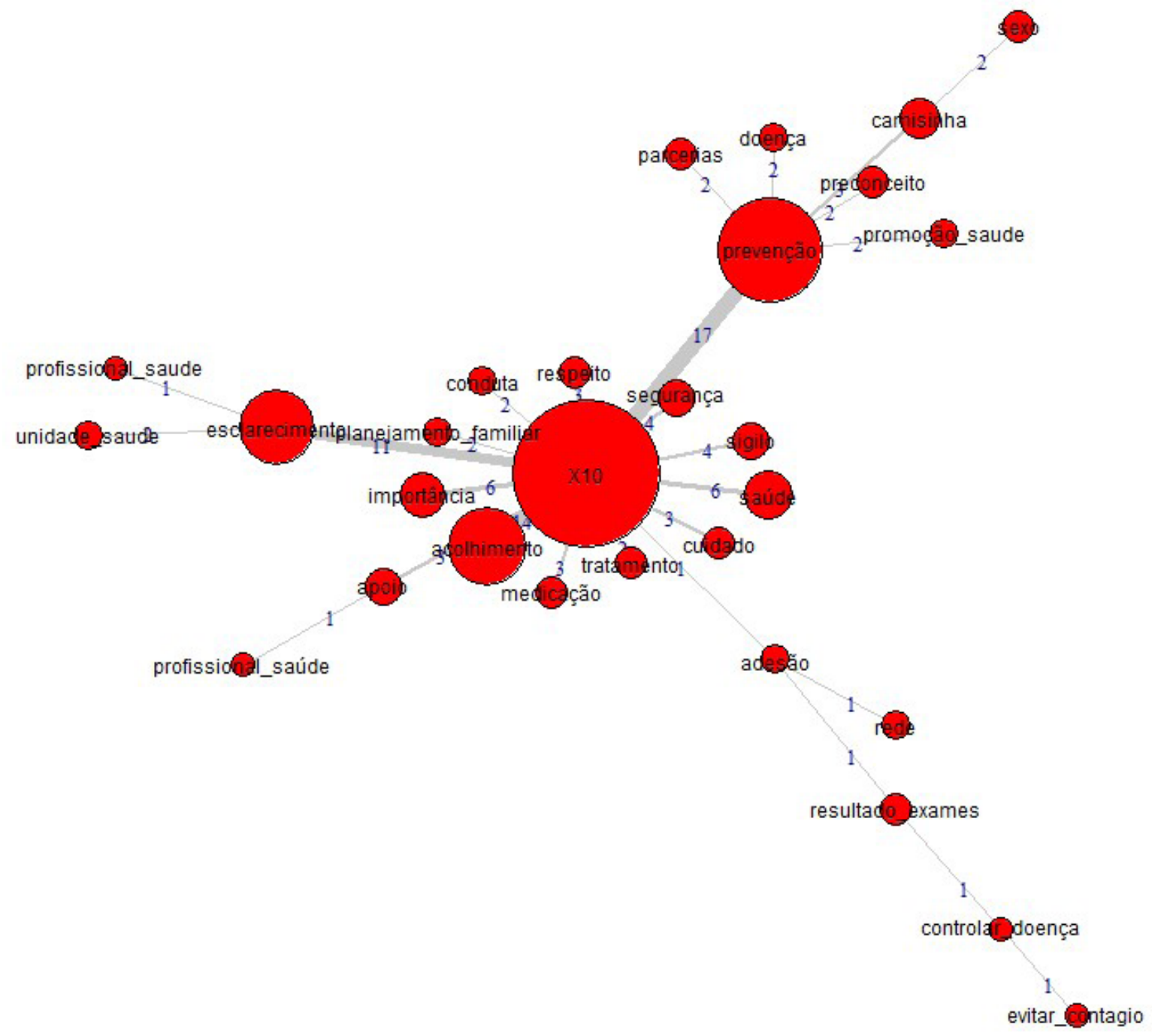

Fonte: Elaboração própria.

\section{Discussão}

A discussão dos dados socioprofissionais (caracterização) e do TALP (quadro de quatro casas e árvore de similitudes) ocorrerá simultaneamente. O processamento dos dados pelo software EVOC teve como produto o Quadro 1, representando o quadro de quatro casas. No quadrante superior esquerdo, as palavras "esclarecimento e prevenção" constituem o provável núcleo central da representação social dos profissionais para o termo indutor utilizado.

Iniciando a análise pelo núcleo central, com base no Quadro 1, a palavra "esclarecimento", evocada 20 vezes, retrata que a prática de aconselhamento requer, por parte dos profissionais, preparação adequada e qualificada, sendo necessária uma explicitação do que realmente o grupo estudado entende por aconselhamento.

É provável que o termo "esclarecimento" conote a relação de poder que historicamente estabeleceu-se entre profissional e usuário/a. Nesse sentido, caso o profissional limite-se a esclarecer o/a usuário/a que necessita de explicações acerca do HIV, equivocadamente o aconselhamento passaria a significar que o profissional é apenas o detentor do saber, resultando, então, 
numa situação de imposição e distanciamento da proposta de acolhimento.

O aconselhamento é uma estratégia de educação em saúde e constitui-se enquanto momento em que acontece a interação profissional e usuário/a, a criação do vínculo com a unidade, a troca de informações e de sentimentos entre aconselhador e aconselhado ${ }^{(15)}$. A educação em saúde envolve sensibilização, esclarecimento e participação de profissionais na problemática da prevenção da infecção pelo HIV, viabilizando um vocabulário claro, mais próximo da realidade do/a usuário/a, para que as informações disponibilizadas sejam acessadas ${ }^{(16)}$.

Para que o acolhimento seja estabelecido na atenção à PVH, é extremamente necessário esclarecer as dúvidas do usuário/a acerca da infecção, reconhecer situações de risco, proporcionar a minimização de medos e preocupações, para além da criação do vínculo entre profissional, equipe de saúde e PVH, estabelecendo, então, uma relação de alteridade e confiança entre os sujeitos envolvidos.

A equipe de saúde poderá entender, no processo de aconselhamento, as dificuldades do/a usuário/a e encontrar a melhor forma de ajudá-lo/a. A representação social do cuidado a pessoas com HIV que vem sendo formada por profissionais de saúde do Rio de Janeiro, Brasil, indicam que esses possuem uma compreensão específica para esse cuidado, por estarem em contato direto e por possuírem interesse profissional no cuidado, já que pessoa com HIV é o principal objeto de trabalho para esses profissionais $^{(17)}$.

Ainda analisando o núcleo central, o termo prevenção, evocado 21 vezes, com OME de 2,048, foi o termo mais prontamente evocado. A prevenção mantém uma relação direta com o HIV e traz a concepção de que uma doença crônica necessita, para seu controle, de ações preventivas. No processo de aconselhamento, são traçadas estratégias de prevenção, ensinadas formas de prevenir e esclarece-se os/as usuários/as sobre a importância e as implicações de serem atuantes no momento de decidir como prevenir-se e reduzir os riscos.
A prevenção realmente está associada ao aconselhamento. É considerada uma estratégia que engrandece o âmbito da testagem e configura-se como uma ação em saúde que contribui para a elaboração de discursos que viabilizam a reflexão do indivíduo frente aos problemas relacionados às IST/HIV/aids. Além disso, fortalece a adoção de medidas que resultarão em maior autonomia do sujeito no processo de prevenção e cuidado ${ }^{(18)}$.

Os termos "prevenção e esclarecimento", que configuram o núcleo central da representação social, convergem e formam praticamente uma única representação, por induzirem ao pensamento de que aconselhamento é um esclarecimento profissional para se chegar ao processo de prevenção.

Existem críticas quanto ao fato de o profissional de saúde que realiza o aconselhamento e executa o papel de agente ativo da relação, ser aquele que dirige as ações do/a usuário/a que, por sua vez, é apresentado como passivo. Assim, no processo em que um recebe a intervenção e é esclarecido, esse encontro parece ser marcado por um circuito instrumental conduzido pelo aconselhador, no qual o usuário recebe orientações para produzir mudanças que possam vir a lhe proporcionar melhor qualidade de vida ${ }^{(19)}$.

Em contrapartida, autores discutem que, quando o discurso do aconselhamento tem como eixo central o favorecimento da autonomia e da autogestão de sujeitos para a prevenção e promoção da saúde, a lógica da prevenção parte do pressuposto de que, por meio da informação e do diálogo, é factível proporcionar à pessoa condições para que avalie seus próprios riscos e maneiras de enfrentar as questões relacionadas às IST/HIV/aids. O estudo realizado com adolescentes no Rio de Janeiro, Brasil, sobre o aconselhamento recebido na ocasião do teste para HIV, revelou que menos de um terço dos adolescentes recebeu aconselhamento pré-teste (30,8\%) e que este resumia-se à explicação do motivo do exame; quanto ao aconselhado pós-teste, cerca de 51,2\% afirmaram ter recebido ${ }^{(20)}$.

O sistema periférico de uma representação social é formado pela primeira e segunda periferia. 
A primeira periferia viabiliza a interface entre a realidade fundamentada e o sistema central e dispõe da característica de apoiar a heterogeneidade e as contradições de grupo. A segunda periferia da representação assegura, de forma parcial, a estabilidade da representação, conferindo uma proteção para o núcleo central ${ }^{(14)}$.

No Quadro 1, a palavra "acolhimento" aparece no sistema periférico próximo, evocado 15 vezes. A ideia de que os profissionais conheciam a política de aconselhamento e a reproduziam em seu discurso, entendendo a sua importância, visibiliza-se na representação dos participantes. A aproximação entre os termos que constituem o núcleo central e a periferia próxima (prevenção, esclarecimento e acolhimento) denota tal importância.

O acolhimento é uma das diretrizes da Política Nacional de Humanização (PNH) embasada em uma tecnologia de cuidado na qual executa-se a escuta qualificada, desde o primeiro contato com o usuário do sistema de saúde, para a efetivação do processo de aconselhamento, que ocorre simultaneamente ao acolhimento. Isso implica em exercer uma escuta sensível, considerando preocupações e angústias do/a usuário/a, o que irá possibilitar uma análise da demanda, colocar os limites necessários, proporcionar a atenção integral, resolutiva e responsável, por meio do acionamento e/ou articulação das redes internas/ externas dos serviços de saúde para continuidade da assistência, quando necessário ${ }^{(21)}$.

A prática do acolhimento deve estar presente em todas as relações de cuidado. Perpassa receber a pessoa, ser responsável por ela, escutar atentamente sua queixa, deixá-la à vontade para procurar o serviço de saúde, facilitar o acesso ao serviço e ao tratamento. Acolher as $\mathrm{PVH}$ abrange sua inclusão no serviço de saúde, considerando suas expectativas e necessidades, e garantir que a equipe de atenção básica busque medidas com vista à ampliação do cuidado ${ }^{(4)}$. No entanto, estudo realizado em nove UBS no estado de Pernambuco verificou fragilidades para a realização dos testes rápidos, dentre elas as relacionadas à logística de materiais e insumos, capacitação para realização do aconselhamento pré e pós-teste, além da necessidade de melhorias nas ações de educação permanente ${ }^{(5)}$.

A periferia próxima, localizada abaixo do núcleo central, denomina-se de zona de contraste e pode apontar elementos que intensificam as noções expostas no núcleo central e na periferia ou evidenciar a existência de um subgrupo que sustente uma representação distinta da maioria do grupo ${ }^{(8)}$. Na zona de contraste (Quadro 1), temos os termos "camisinha, cuidado, importância, sexo e preconceito", que remetem aos temas geralmente abordados no exercício do aconselhamento pelos profissionais de saúde.

Durante o aconselhamento, é importante que se fale do uso da camisinha como forma de prevenção e de cuidados à saúde no momento do ato sexual, visto que essa é a forma mais segura de prevenção, autocuidado e autonomia frente a um agravo de transmissão sexual. Entretanto, o termo "preconceito", evocado apenas 3 vezes, aponta que, apesar de tantas discussões acerca do HIV, o/a usuário/a sofre com o estigma. Na medida em que os próprios profissionais de saúde atribuem valor a um termo tão presente no início da epidemia, podem estar desconsiderando as mudanças que ocorreram com o passar dos anos e consolidando aspectos negativos ainda arraigados em suas representações.

Nesse sentido, os profissionais de saúde devem buscar estratégias que possibilitem garantir os direitos humanos de usuários/as do serviço, pois têm o encargo de refletir e combater toda e qualquer forma de preconceito e discriminação associada a questões relacionadas ao exercício da sexualidade, ao uso de drogas e às infecções sexualmente transmissíveis. Precisam estar sempre atentos para reverter situações, nas quais são evidenciadas atitudes preconceituosas, considerando que todas as pessoas possuem direito a saúde e precisam ser acolhidas com respeito $^{(4)}$. Entretanto, o medo que é evidenciado pelo "preconceito" pode interferir na qualidade do acolhimento e no processo do aconselhamento. Doenças que provocam medo são julgadas letais e desumanizadoras. A aids, sendo uma doença ancorada na peste, traz à tona a 
metáfora de um dos piores males estigmatizados na história da humanidade ${ }^{(9)}$.

$\mathrm{Na}$ periferia distante do Quadro 1, o termo "unidade de saúde" traz a ideia de que os profissionais compreendem e atribuem importância ao papel das UBS no momento do aconselhamento/ acolhimento. Os termos doença, medicação, saúde e tratamento remetem às ações que se associam à terapia antirretroviral (TARV) instituída nos anos 90 e que impactou de forma determinante na estimativa de vida das pessoas com HIV. Ao distanciar a TARV do núcleo central da representação social, os profissionais de saúde indicam que "tratamento, medicação e doença" vêm perdendo importância frente à necessidade de esclarecimento e de ações de prevenção na política de atenção a PVH.

É forçoso expor que, ao mesmo tempo em que a representação constrói uma familiarização com o novo e se adapta em categorias precocemente conhecidas, ela também pode desempenhar uma função de classificação no âmbito de tais categorias, tendo em vista que o objeto da representação pode delas aproximar-se ou distanciar-se ${ }^{(22)}$.

Os termos "promoção de saúde e resultado de exames" agregam-se à representação e demonstram uma compreensão de que o aconselhamento é uma forma de promoção de saúde que permite às/aos usuárias/os desvelar diversas questões acerca da infecção pelo HIV. É imprescindível que toda testagem para o HIV seja acompanhada de aconselhamento pré e pós-teste, e sempre com o consentimento do/a usuário/a. A comunicação do resultado é um momento difícil, que acaba exigindo habilidade do profissional de saúde para fazê-lo, visto que pode desencadear estresse psicológico no/a usuário/a. A equipe de saúde precisa estar apta para reduzir o impacto do diagnóstico, se o resultado for positivo, e apresentar bons argumentos para intensificar as práticas preventivas no caso de resultado negativo ${ }^{(3)}$.

Os termos "apoio, sigilo, respeito e segurança" mostram-se associados à postura assumida pelo profissional de saúde no momento do acolhimento, conforme normatização da PNH.
Ao assumir a postura de acolhimento, o profissional poderá atender o/a usuário/a em toda a sua singularidade, resultando em uma relação de confiança, em que provavelmente o/a usuário/a sentirá que pode expressar todos os seus sentimentos e suas dúvidas acerca do HIV.

O aconselhador desempenha as tarefas de educar, orientar e manter-se em postura vigilante, estando atento à maneira como esse cuidado é prestado. Por conseguinte, deve-se considerar o local e o momento oportunos, garantindo o sigilo e a transmissão de segurança, para que o/a usuário/a possa falar de si. Cabe, então, ao profissional escutá-lo/a em sua singularidade, de modo que venha a adquirir confiança ${ }^{(23)}$.

O termo "parcerias", que também aparece na periferia distante, subentende que os profissionais estão cientes da importância de parceiros sexuais no acolhimento, sejam eles/as, casais sorodiscordantes ou não, bem como a comunicação da sorologia ao/a parceiro/a, caso este desconheça. Cabe-lhes também orientar quanto à convivência com o HIV, adotar medidas de prevenção sexual como o uso do preservativo masculino ou feminino e apontar a direção do cuidado integral na oferta da testagem, tendo em vista o número crescente de casais sorodiscordantes.

A comunicação dos/as parceiros/as obedecerá aos princípios da confidencialidade, ausência de coerção e proteção contra a discriminação. Nesse aspecto, a testagem da parceria sexual soronegativa deve ser oferecida quando ocorrer exposição sexual de risco, ou mesmo periodicamente, devendo-se individualizar essa conduta $^{(3)}$.

Os casais sorodiscordantes enfrentam um grande problema que é a transmissão do HIV, em especial em parcerias estáveis, porém uma série de fatores pode influenciar o risco de transmissão nessas relações, sobretudo o comportamento sexual desses casais e a presença da IST $^{(24-25)}$. Desse modo, fica evidente a necessidade do aconselhamento desses casais.

A árvore de similitude (Figura 1), apresenta termos semelhantes aos expostos no quadro de quatro casas (Quadro 1). Em seus quatro eixos, 
possibilita identificar a co-ocorrência entre os termos. O eixo I mostra maior densidade, por conter mais elementos, dentre eles um denominado "x10", que é uma variável do banco de dados utilizada para aglutinar as profissionais mulheres, configurando-se como o elemento com maior número de termos agregados.

Assim, a variável sexo feminino (x10) centraliza o eixo I e possui maior força de conexão com os demais eixos. O eixo II está representado pelo termo "prevenção", evocado 17 vezes. O eixo III constitui-se com base no termo "esclarecimento", evocado 11 vezes, e o eixo IV, pela palavra "acolhimento", evocada 14 vezes.

A Figura 1 tem sua periferia configurada pelos termos segurança, sigilo, saúde, importância, tratamento e medicação, que também configuram a periferia distante do quadro de quatro casas (Quadro 1).

No eixo II, o termo "prevenção" associa-se às palavras "parcerias, doença, preconceito, camisinha, sexo e promoção de saúde", trazendo a ideia de possíveis temáticas abordadas durante o processo de aconselhamento. A associação desses termos sinaliza o caminho a ser percorrido para alcançar a prevenção, que sobreleva a importância do sexo protegido. No entanto, o termo "preconceito", presente nesse eixo e na zona de contraste do quadro, destoa, pelo fato de esta não dever ser a conduta adotada por profissionais que lidam com o HIV.

O termo "esclarecimento", que aglomera o eixo III e conecta-se aos termos "profissionais de saúde e unidade de saúde", aliado aos anos de experiência profissional dos participantes deste estudo, já que 35 deles possuem grau de especialização e 24 têm idade acima de 35 anos, permite entender-se que provavelmente esses profissionais valorizam o desenvolvimento de atividades educativas (70,2\%), como afirmaram executá-las nas unidades de saúde.

O termo "acolhimento" centraliza o eixo IV e associa-se a "apoio e profissional de saúde", denotando que as/os participantes reconhecem possuir a função de prestar apoio a $\mathrm{PVH}$ enquanto realizam o acolhimento, uma vez que o apoio do profissional contribuirá para a criação do vínculo e possibilitará ao/a usuário/a expor seus sentimentos diante da possibilidade de uma positividade sorológica.

Destaca-se como limitação da pesquisa o fato de ter sido um estudo local. Além disso, apesar de ter envolvido todos os profissionais da atenção básica com graduação e pós-graduação, considera-se oportuno estudos de continuidade em hospitais e outros cenários, para se conhecer diferentes realidades e ampliar as percepções dos sujeitos acerca da temática, buscando enriquecer os resultados obtidos.

\section{Conclusão}

As representações sociais dos profissionais participantes acerca do acolhimento retratam uma representação normativa e hegemônica, por enfatizar as políticas públicas voltadas ao acolhimento da pessoa com HIV. Notou-se que a centralidade da representação é mantida tanto na análise do quadro de quatro casas quanto na análise da árvore de similitude.

Nesta pesquisa, a representação foi objetivada na prevenção e no esclarecimento. Revelou conhecimento técnico dos participantes e demarcou possivelmente o lugar de "detentores do conhecimento" em questões ligadas ao acolhimento, o que poderá gerar uma situação equivocada de imposição e um distanciamento da política governamental.

As representações sociais dos/as participantes desvelam necessidades e importância de acolhê-los com base em protocolos e apontam uma possível postura centralizadora dos profissionais, ao não revelarem se o usuário também participa do processo de acolhimento.

\section{Colaborações:}

1. concepção, projeto, análise e interpretação dos dados: Fabiane da Silva Santos e Cleuma Sueli Santos Suto;

2. redação do artigo e revisão crítica relevante do conteúdo intelectual: Silvana Gomes Nunes Piva e Gizélia dos Santos Souza; 
3. aprovação final da versão a ser publicada:

Taciane Oliveira Bet Freitas e Rita de Cassia Dias Nascimento.

\section{Referências}

1. Brasil. Ministério da Saúde do Brasil. Hiv, aids. Bol Epidemiológico HIV Aids. 2017;64:22-3.

2. Brasil. Ministério da Saúde. Boletim Epidemilógico HIV/AIDS. 2015;1:1-100.

3. Brasil. Ministério da Saúde. HIV/AIDS, Hepatite e Outras DSTs. Cad Atenção Básica. 2006;18:1-196.

4. Brasil. Ministério da Saúde. Cuidado integral às pessoas que vivem com HIV pela Atenção Básica. Manual para a equipe multiprofissional. Brasília; 2015.

5. Araújo WJ, Quirino EMB, Pinho CM, Andrade MS. Perception of nurses who perform rapid tests in Health Centers. Rev Bras Enferm [Internet]. 2018 [cited 2018 jul 17];71(Suppl 1):631-6. [Thematic Issue: Contributions and challenges of nursing practices in collective health]. Available from: DOI: http://dx.doi.org/10.1590/0034-7167-2017-0298

6. Zakabi D. Aconselhamento pré e pós-teste anti-HIV na atenção básica: a perspectiva dos profissionais de saúde [dissertação]. [São Paulo]: Faculdade de Medicina da Universidade de São Paulo; 2012.

7. Costa PCP, Garcia APRF, Toledo VP. Welcoming and nursing care: a phenomenological study. Texto contexto-enferm [Internet]. 2016 [cited 2018 Jul 7];25(1):e4550015. Available from: http://www.scielo.br/scielo.php?script= s c i_art text \& p i d = S $0104-070720$ 16000100324\&lng=en. http://dx.doi.org/10.1590/ 0104-07072016004550014

8. Costa TL, Oliveira DC, Formozo GA, Gomes AMT. Pessoas com HIV/Aids nas representações sociais de enfermeiros: análise dos elementos centrais, contranormativos e atitudinais. Rev Latino-Am Enfermagem. 2012;20(6):1091-9.

9. Oliveira DC. Construction and transformation of social representations of AIDS and implications for health care. Rev Latino-Am Enfermagem. 2013;21(spe):276-86.

10. Gazzinelli MFC, Marques RDC, Oliveira DC, Amorim MMA, Araújo EG. Representações sociais da educação em saúde pelos profissionais da equipe de saúde da família. Trab Educ e Saúde. 2013;11(3):553-71.
11. Shimizu HE, Silva JR, Moura LM, Bermúdez XPD, Odeh MM. A estrutura das representações sociais sobre saúde e doença entre membros de movimentos sociais. Ciênc saúde coletiva [Internet]. 2015 Sep [cited 2018 Jul 27];20(9):2899910. Available from: http://www.scielo.br/scielo. php? script $=$ sci_arttext $\&$ pid $=S 1413-81232$ 015000902899\&lng=en. http://dx.doi.org/10.1590/ 1413-81232015209.20592014

12. Sá CP. Estudos de psicologia social: história, comportamento, representações e memória. Rio de Janeiro: EdUERJ; 2015.

13. Camargo BV, Justo AM. IRAMUTEQ: um software gratuito para análise de dados textuais. Temas em Psicol. 2013;21(2):513-8.

14. Machado YY, Nogueira VPF, Oliveira DC, Nogueira VPF, Gomes AMT. Health personnel's social representations of HIV/AIDS: a structural analysis. Rev Enferm UERJ [Internet]. 2016 [cited 2018 Jul 17];24(1):e14463. Available from: https://www.e-publicacoes.uerj.br/index.php/ enfermagemuerj/article/view/14463/17866. DOI: http://dx.doi.org/10.12957/reuerj.2016.14463

15. Moreno DMFC, Reis AOA. Revelação do diagnóstico da infecção pelo HIV no contexto do aconselhamento: a versão do usuário. Temas em Psicol. 2013;21:59-609.

16. Araújo GM, Nardino LJ, Resdorfer N, Begnini D. Aconselhamento pré-testagem rápida: uma proposta de educação em saúde. Rev Espaço Ciênc Saúde [Internet]. 2017 [cited 2018 Jul 20];5(1):6173. Available from: http://revistaeletronica.unicruz. edu.br/index.php/enfermagem/article/view/5493

17. Nogueira VPF, Gomes AMT, Machado YY, Oliveira DC. Cuidado em saúde à pessoa vivendo com HIV/AIDS: representações sociais de enfermeiros e médicos. Rev Enferm UERJ [Internet]. 2015 [cited 2018 Jul 22];23(3):331-7. Available from: http://www.facenf.uerj.br/v23n3/v23n3a07.pdf. DOI: http://dx.doi.org/10.12957/reuerj.2015.14466

18. Fonseca PL, Iriart JAB. Aconselhamento em DST/ Aids às gestantes que realizaram o teste anti-HIV na admissão para o parto: os sentidos de uma prática. Interface Common Heal Educ. 2012;16(41):395-407.

19. Cristina W, Galindo M, Rios LF. Reflexões sobre o Trabalho de Aconselhamento em HIV/Aids. Trends Psychol. 2015;23(4):815-29.

20. Taquette SR, Rodrigues AO, Bortolotti LR. Perception of pre- and post-HIV test counseling among patients diagnosed with aids in 
adolescence HIV test counseling for adolescents. Ciênc. saúde coletiva [Internet]. 2017 Jan [cited 2018 July 27];22(1):23-30. Available from: http://www.scielo.br/scielo.php?script=sci_ arttext\&pid=S1413-81232017000100023\&lng=en. http://dx.doi.org/10.1590/1413-81232017221. 23532015.

21. Brasil. Ministério da Saúde. HumanizaSus: documento base para gestores e trabalhadores do SUS. Série B. Textos Básicos de Saúde. Brasília; 2010. 72 p.

22. Maria C, Loureiro S, Dantas M, Unifor DF. As Representações Estigmatizadas Sobre Portadores de HIV / AIDS em uma Casa de Apoio. IV Congresso Brasileiro de Estudos Organizacionais; 2016 out 19-out 21; Porto Alegre, RS. Anais [Internet]. Porto Alegre, RS; 2016 [cited 2018 Jul 14]. Available from: https://anaiscbeo.emnuvens. com.br/cbeo/article/view/53/45
23. Cristina W, Galindo M, Francisco AL. A instrução e a relação como modos de aconselhamento em HIV/Aids. Temas Psicol. 2013;21(3):989-1004.

24. Van Tam V, Cuong DD, Alfven T, Phuc HD, Chuc NTK, Hoa NP, et al. HIV sero-discordance among married HIV patients initiating anti-retroviral therapy in northern Vietnam. AIDS Res Ther. 2016;13(1):39.

25. Oliveira LB, Matos MCB, Jesus GJ, Reis RK, Gir E, Araujo TME. Sexual partnerships of people living with the Human Immunodeficiency Virus. Rev Rene [Internet]. 2017 [cited 2018 July 11];18(6):825-31. Available from: http:// periodicos.ufc.br/rene/article/view/31103. DOI: 10.15253/2175-6783.2017000600017

Recebido: 22 de agosto de 2018

Aprovado: 20 de março de 2019

Publicado: 18 de junho de 2019

A Revista Baiana de Enfermagem utiliza a Licença Creative Commons - Atribuição-NãoComercial 4.0 Internacional. https://creativecommons.org/licenses/by-nc/4.0/ Este artigo é de acesso aberto distribuído sob os termos da Licença Creative Commons (CC BY-NC). Esta licença permite que outros remixem, adaptem e criem a partir do seu trabalho para fins não comerciais. Embora os novos trabalhos tenham de lhe atribuir o devido crédito e não possam ser usados para fins comerciais, os usuários não têm de licenciar esses trabalhos derivados sob os mesmos termos. 